\title{
DIVERSITY OF INTERTIDAL MACROALGAE INCREASES WITH NITROGEN LOADING BY INVERTEBRATES
}

\author{
Matthew E. S. BRaCKen ${ }^{1,3}$ And Karina J. Nielsen ${ }^{2}$ \\ ${ }^{1}$ Department of Zoology, Oregon State University, Corvallis, Oregon 97331-2914 USA \\ ${ }^{2}$ Sonoma State University, Department of Biology, Rohnert Park, California 94928 USA
}

\begin{abstract}
Many ecological phenomena are characterized by context dependency, and the relationship between diversity and productivity is no exception. We examined the relationship between macroalgal diversity and nutrient availability by evaluating the effects of reduced nutrients and their subsequent replacement via local-scale nutrient loading in tide pools. Macroalgae in Oregon coast high-intertidal pools have evolved in a nitrate-rich upwelling ecosystem, but instead of settling on low-intertidal reefs (where algae are often immersed in nutrient-rich nearshore waters) these individuals have colonized high-zone pools, where they are isolated from the ocean for extended periods of time and are subjected to extended periods of nitrate depletion. In some pools, this nutrient stress was ameliorated by a positive interaction: the excretion of ammonium by invertebrates. We conducted experimental manipulations to quantify invertebrate-mediated ammonium loading and macroalgal ammonium uptake in high-intertidal pools. Variation in tide pool volume and invertebrate biomass created a gradient of local-scale nutrient inputs, allowing us to address the relationship between nitrogen loading and algal diversity. Slow-growing species tolerant of low nitrogen availability were joined by fast-growing species with higher nitrogen requirements in pools with higher ammonium loading rates. A fourfold increase in the ammonium loading rate was associated with a doubling in the number of macroalgal species, and macroalgal assemblages in more species-rich pools were characterized by higher rates of biomass-specific ammonium uptake. These patterns contrast with productivity-diversity relationships in terrestrial systems, where local-scale nutrient enrichments generally result in reduced producer diversity due to displacement of subordinate species by aggressive competitors. Our data suggest that the effect of enrichment on diversity is context-dependent. Each ecosystem has a critical level of nutrient availability, determined by the level of nutrients typically available in that system. Below this critical level, local-scale nutrient additions increase diversity, but above it, diversity declines with enrichment.
\end{abstract}

Key words: diversity; facilitation; macroalgae; nitrogen uptake; nutrients; positive interactions; productivity; rocky intertidal; species richness; tide pools.

\section{INTRODUCTION}

Humans impact both the productivity of ecosystems and their species diversity. The current rate of anthropogenic nitrogen fixation is more than twice that of natural processes (Vitousek 1994), and extinction rates are increasing worldwide (Pimm et al. 1995). Because diversity both affects and is affected by productivity (Naeem 2002), understanding diversity, productivity, and their relationship is both a scientific and a societal concern.

However, the influence of increasing productivity on diversity is unclear. Both theoretical and empirical evidence suggest that diversity can be an increasing (Connell and Orias 1964, Hall et al. 2000), decreasing (Riebesell 1974, Tilman 1987), or unimodal (Leibold 1999,

Manuscript received 1 October 2003; revised 30 March 2004; accepted 2 April 2004. Corresponding Editor (ad hoc): S. L. Williams.

${ }^{3}$ Present address: Section of Evolution and Ecology and Bodega Marine Laboratory, University of California at Davis, P.O. Box 247, Bodega Bay, California 94923-0247 USA. E-mail: mebracken@ucdavis.edu
Kassen et al. 2000) function of productivity. Especially in terrestrial systems, most experimental increases in productivity (via addition of limiting nutrients) result in declines in macrophyte diversity, due to domination by aggressive competitors (Gough et al. 2000). Rosenzweig (1995) argues that this "paradox of enrichment" occurs because the autotrophs in an ecosystem are adapted to coexist at that system's typical level of productivity. Adding nutrients predictably destabilizes this coexistence, reducing the number of species.

In contrast, in nutrient-limited aquatic systems, nutrient additions often result in an increase in diversity up to a threshold, as species tolerant of low nutrient availability are supplemented by species with higher nutrient requirements. Nutrient enrichment beyond the threshold is marked by a decline in diversity, resulting in a unimodal relationship between productivity and diversity (Mittelbach et al. 2001, Worm et al. 2002). In these systems, local variation in nutrient availability can influence macrophyte biomass and diversity over small spatial scales (Nielsen 2001, 2003).

For example, on the Oregon coast, high-zone tide pools contain assemblages of macroalgae adapted to a 
high productivity upwelling ecosystem: nitrate levels in the adjacent coastal ocean often exceed $20 \mu \mathrm{mol} / \mathrm{L}$ (Fujita et al. 1989, Menge et al. 1997a). However, in contrast to low-intertidal reefs, where macroalgae are almost continuously immersed in a nutrient-replete environment (i.e., both high nutrient levels and flow rates), high-intertidal pools are isolated from oceanic inputs of new nitrogen (sensu Dugdale and Goering 1967), and algae in the pools experience still-water conditions for extended periods of time. High-zone pools contain many species found lower in the intertidal zone (Johnson and Skutch 1928; M. Bracken, personal observation), but individuals in the pools live in a much less productive microhabitat. Addition of nutrients to Oregon coast tide pools results in increased macroalgal diversity (evenness of functional groups) and total macroalgal biomass, suggesting that some tide pool macroalgae are nutrient limited, despite high nitrate availability in the adjacent nearshore ocean (Nielsen 2001 , 2003). Because high-intertidal pools are nutrient-poor microhabitats within a typically nutrient-replete ecosystem, we were functionally able to quantify the influences of reduced nutrient availability on diversity.

Invertebrates can excrete substantial quantities of ammonium into tide pools (Jensen and Muller-Parker 1994), and a growing body of evidence indicates that invertebrates' nitrogenous excretory products can provide an important local-scale nutrient source for macroalgae (Williams and Carpenter 1988, Taylor and Rees 1998). Invertebrates may thereby have a positive effect on macroalgae by reducing the stress associated with nutrient limitation in high-intertidal pools. Variation in both the volume of tide pools and the biomass of invertebrates in them creates a natural gradient of local-scale nutrient inputs into pools. Here, we describe manipulations and measurements that quantified the depletion of nitrate in emersed pools, the excretion of ammonium by tide pool invertebrates, the utilization of excreted ammonium as a nutrient source by macroalgae, and the association between ammonium loading and algal diversity.

\section{Methods}

\section{Site and tide pool characteristics}

Studies were conducted at three sites on the coast of Oregon, USA: Strawberry Hill $\left(44^{\circ} 15.3^{\prime} \mathrm{N}, 124^{\circ} 06.7^{\prime}\right.$ $\mathrm{W}$; hereafter $\mathrm{SH})$, Bob Creek $\left(44^{\circ} 14.7^{\prime} \mathrm{N}, 124^{\circ} 06.7^{\prime}\right.$ $\mathrm{W}$; BC), and Boiler Bay (4450.0' N, $124^{\circ} 03.7^{\prime} \mathrm{W}$; BB). At $\mathrm{SH}$ and $\mathrm{BC}$, reefs extended into the high-intertidal zone. Natural tide pools contained substantial biomasses of both invertebrates (primarily Mytilus californianus Conrad) and macroalgae. All SH and BC pools ( $n=10$ per site) were located at approximately the same tide height, $\sim 2.1 \mathrm{~m}$ above mean lower-low water. These pools were used to measure ammonium fluxes and algal diversity during June 2000 (SH) and July 2002 (BC).
BB is characterized by broad mudstone reefs in which tide pools were chiseled for a previous set of experiments (Nielsen 2001, 2003). Because of the rapidly eroding mudstone substrate, BB pools were not colonized by mussels (K. Nielsen, unpublished data). Experimental herbivore removals resulted in low overall invertebrate biomass, facilitating estimates of macroalgal nitrate uptake. Therefore, BB pools $(n=6)$ were used to evaluate nitrate depletion.

\section{Nitrate limitation in high-zone tide pools}

When measurements of nitrate uptake were conducted, two years after the BB pools were created, the macroalgal diversity and biomass in them were similar to SH and BC pools (Nielsen 2001, 2003). The BB pools had not received any substantial disturbance for two years, which corresponds to the average time between disturbances in natural tide pools (Dethier 1984). We evaluated macroalgal depletion of nitrate in BB pools because they were characterized by low ratios of invertebrate biomass to pool volume $(0.5 \pm 0.1 \mathrm{~g} / \mathrm{L}$; mean $\pm 1 \mathrm{SE})$. It was impossible to accurately measure nitrate uptake in $\mathrm{SH}$ and $\mathrm{BC}$ tide pools because the presence of invertebrates confounded measurement of nitrate depletion due to oxidation of invertebrate-excreted ammonium by nitrifying bacteria (M. Bracken, unpublished data). Water samples were collected from each BB pool at $0.0,2.6$, and $5.4 \mathrm{~h}$ after isolation by the receding tide. Samples were filtered through a Whatman GF/F glass-fiber filter (Whatman, Maidstone, $\mathrm{UK})$, transported to the laboratory on ice, and stored at $-20^{\circ} \mathrm{C}$ prior to analysis. Nitrate concentrations were determined on a spectrophotometer after reduction with cadmium and addition of sulfanilamide and NEDA to form an azo dye (Parsons et al. 1984).

Nitrate depletion rates were estimated for the $\mathrm{SH}$ and $\mathrm{BC}$ pools from known relationships between pool volumes, algal biomass:pool volume ratios, and average number of hours isolated. Tide pool volumes were determined by siphoning the water from each pool into a graduated bucket. Emersion durations were calculated by determining, by observation, the time at which the ebbing tide isolated the pools, then using tide-prediction software (Tides \& Currents for Windows, version 2.5b, Nautical Software, Inc., Beaverton, Oregon, USA) to estimate emersion durations over the two years spanning this study.

\section{Ammonium fluxes in high-zone tide pools}

We took water samples $(1 \mathrm{~mL})$ from $\mathrm{SH}$ and $\mathrm{BC}$ tide pools ( $n=10$ per site) at intervals after the receding tide isolated the pools and determined ammonium concentrations using the phenol-hypochlorite method (Solórzano 1969). Because of the diel progression in the tidal cycle, SH pools were emersed 2.3-3.8 h before sunrise (depending on the day), and samples were taken at $-1,0,1$, and $2 \mathrm{~h}$ before and after sunrise. Additionally, we collected a sample from each SH pool as 
it was isolated by the falling tide. BC pools were isolated during the afternoon, and samples were taken 0 , 1,2 , and $4 \mathrm{~h}$ after pool emersion. We conducted sampling and manipulations over the course of three days at each site. On day 1 , we measured ammonium fluxes in intact pools. Then we removed all macroalgal biomass from each pool. On day 2, we again measured ammonium fluxes in each pool, then removed all invertebrates from the pools. Finally, on day 3, we measured ammonium concentrations in the absence of both invertebrates and macroalgae. We determined the ashfree dry masses of all invertebrate and macroalgal tissues from each pool for calculation of mass-normalized ammonium excretion and uptake rates based on the measurements above. We defined the rate of ammonium loading as the ammonium accumulation rate $\left(\mu \mathrm{mol} \cdot \mathrm{L}^{-1} \cdot \mathrm{h}^{-1}\right)$ in the absence of macroalgae.

\section{Herbivore densities and macroalgal diversity}

Densities of the turban snail Tegula funebralis A. Adams, a major herbivore in Oregon-coast tide pools (Nielsen 2001), were determined in SH pools $(n=10)$ prior to experimental manipulations. Visual counts of Tegula were divided by pool surface area to estimate the impact of herbivory (number of individuals per square meter). We measured the surface area of each SH and BC pool's bottom after siphoning out the water to estimate volume. A flexible mesh "quadrat" (Foulweather Trawl Supply, Newport, Oregon, USA) was spread over the bottom of each pool to calculate surface area and percentage cover of all macroalgal species. We quantified macroalgal diversity in all $\mathrm{SH}$ and $\mathrm{BC}$ pools ( $n=10$ per site) using the algae removed from each pool in the manipulations described above; all macroalgae were identified to species.

\section{Ammonium uptake experiments}

Individuals of Ulva californica Wille and Prionitis lanceolata Harvey ( $n=15$ each) were collected from a single high-intertidal pool at BC. Our surveys at SH and $\mathrm{BC}$ indicated that Ulva was found only in pools characterized by high rates of ammonium accumulation, while Prionitis occurred in pools with both low and high ammonium loading rates. Algae were rinsed with seawater to remove sediment and epiphytes and maintained overnight in a $40-\mu \mathrm{m}$-filtered running-seawater system on a simulated sunrise and sunset cycle prior to uptake measurements.

We measured ammonium uptake using the multiplecontainer, constant-incubation-time method (Harrison and Druehl 1982). Each algal thallus was placed in a beaker containing $100 \mathrm{~mL}$ of filtered seawater. Ammonium $\left(\mathrm{NH}_{4} \mathrm{Cl}\right)$ was added to each beaker so that individual macroalgae were supplied with initial concentrations of ammonium ranging from 2 to $60 \mu \mathrm{mol} /$ L. While most protocols indicate that water circulation is necessary (Harlin and Wheeler 1985), our beakers were not stirred, to simulate the still-water conditions in emersed tide pools. Beakers were illuminated by full-spectrum fluorescent lamps, which provided 77.4 $\pm 1.2 \mu \mathrm{mol}$ quanta $\cdot \mathrm{m}^{-2} \cdot \mathrm{s}^{-1}$ (mean $\pm 1 \mathrm{SE}$ ) photosynthetically active radiation. While these light intensities were low relative to full sunlight, maximum ammonium uptake rates occur at $\sim 40 \mu \mathrm{mol}$ quanta $\cdot \mathrm{m}^{-2} \cdot \mathrm{s}^{-1}$ (Taylor et al. 1998), as macroalgal ammonium uptake does not require high irradiance levels (Wheeler 1982). Water samples $(1 \mathrm{~mL})$ were collected from each beaker at 0.0 and $0.5 \mathrm{~h}$ and analyzed for ammonium using the phenol-hypochlorite method (Solórzano 1969). Each thallus was then dried to constant mass at $50^{\circ} \mathrm{C}$. The change in each beaker's ammonium concentration over the 30min incubation period was divided by the dry tissue mass to evaluate the biomass-specific uptake rate of each individual $\left(\mu \mathrm{mol} \cdot \mathrm{h}^{-1} \cdot \mathrm{g}^{-1}\right)$ as a function of the initial ammonium concentration.

Most studies of macroalgal nutrient uptake use the Michaelis-Menten equation to relate the uptake rate $\left(\mu \mathrm{mol} \cdot \mathrm{h}^{-1} \cdot \mathrm{g}^{-1}\right)$ and nutrient concentration (Harlin and Wheeler 1985). However, because of still-water conditions, ammonium uptake rates did not saturate, based on linear transformations of the data to estimate Michaelis-Menten nutrient uptake coefficients (Ulva, $P=$ 0.6492, $r^{2}=0.02$; Prionitis, $\left.P=0.8652, r^{2}<0.01\right)$. The lack of saturation and low overall uptake rates indicated that diffusion was the likely ammonium-uptake mechanism, probably due to formation of boundary layers in the still water (Hurd 2000), and we used a linear fit to describe the relationship between ammonium uptake and concentration.

\section{Statistical analyses}

We conducted general linear models (GLMs) and $t$ tests using the SAS System for Windows version 8 (SAS Institute, Inc., Cary, North Carolina, USA). GLMs included analyses of variance (ANOVA) and repeated-measures ANOVA. We verified the assumption of normality for $t$ tests by calculating the ShapiroWilk and Kolmogorov-Smirnov statistics. We verified GLM assumptions of normality and homogeneity of variances by visually examining residual plots and normal probability plots of the residuals. In many cases, it was necessary to $\log$ transform $\left(\log _{10}[x]\right.$ or $\log _{10}[x+$ 1]) the data to satisfy model assumptions. Variance in the GLMs was partitioned using Type III sums of squares, which provided balanced tests for the effect of each factor in the model, after accounting for every other factor. We initially ran full models containing all main effects and interactions; interactions were included to assess model fit. If interactions were clearly not significant $(P>0.20)$ they were removed, and we present reduced models containing only main effects (Ramsey and Schafer 1997).

\section{RESULTS}

Nitrogen limitation in high-intertidal pools

Nitrate concentrations in the nearshore ocean were high $(27.2 \pm 2.7 \mu \mathrm{mol} / \mathrm{L}$; mean $\pm 1 \mathrm{SE})$ during this 
study, but macroalgal uptake reduced nitrate concentrations at a rate of $4.1 \pm 0.3 \mu \mathrm{mol} \cdot \mathrm{L}^{-1} \cdot \mathrm{h}^{-1}$, so nitrate was completely exhausted from BB pools $7.2 \pm 0.9 \mathrm{~h}$ after isolation by the receding tide. The pools at $\mathrm{SH}$ and $\mathrm{BC}$, which are at a height of $2.1 \pm 0.2 \mathrm{~m}$ above mean lower-low water, were isolated from the ocean for an average of $12.8 \pm 0.2 \mathrm{~h}$ during each emersion, with periodic isolations of up to $4.7 \mathrm{~d}$ during neap tides. Algal biomasses $(\mathrm{g} / \mathrm{L})$ in the $\mathrm{SH}$ and $\mathrm{BC}$ pools were similar to those at $\mathrm{BB}\left(F_{2,23}=2.43, P=0.1105\right)$, so we assumed that in the absence of invertebrates, depletion of nitrate would occur approximately $7.2 \mathrm{~h}$ after isolation. Thus, in the absence of invertebrates, macroalgae in high-zone pools at $\mathrm{SH}$ and $\mathrm{BC}$ would be without nitrogen for an average of $5.6 \pm 0.2 \mathrm{~h}$ during each emersion. This estimate is conservative, as nitrate concentrations are only high during upwelling, upwelling is not persistent in this region, and nitrate can be completely depleted for several days during relaxation events (Menge et al. 1997b; K. Nielsen, unpublished data).

\section{Ammonium fluxes in tide pools}

Sequential removals of macroalgae and invertebrates affected the ammonium concentrations in $\mathrm{BC}$ and $\mathrm{SH}$ tide pools (Fig. 1). After accounting for site differences (i.e., site was included as a factor in the statistical models), macroalgal removals increased ammonium accumulation rates by $3.8 \pm 0.6 \mu \mathrm{mol} \cdot \mathrm{L}^{-1} \cdot \mathrm{h}^{-1}(\mathrm{re}-$ peated-measures ANOVA: $\left.F_{1,18}=99.76, P<0.0001\right)$, and subsequent invertebrate removals decreased ammonium accumulation rates by $3.4 \pm 0.6 \mu \mathrm{mol} \cdot \mathrm{L}^{-1} \cdot \mathrm{h}^{-1}$ (repeated-measures ANOVA: $F_{1,18}=81.24, P<$ 0.0001 ). Based on these ammonium fluxes and the biomasses of macroalgae and invertebrates removed, invertebrates excreted ammonium into the pools at a rate of $0.5 \pm 0.1 \mu \mathrm{mol} \cdot \mathrm{h}^{-1} \cdot \mathrm{g}^{-1}(t=4.4, \mathrm{df}=19, P=$ $0.0003)$, and macroalgae took up that excreted ammonium at a rate of $1.8 \pm 0.3 \mu \mathrm{mol} \cdot \mathrm{h}^{-1} \cdot \mathrm{g}^{-1}(t=5.4$, $\mathrm{df}=19, P<0.0001)$. Algal biomass in pools ranged from 1.0 to $9.0 \mathrm{~g} / \mathrm{L}$. Pool volumes ranged from 2 to 50 $\mathrm{L}$, and invertebrate biomasses ranged from 6.3 to 561.2 $\mathrm{g}$, creating a gradient in ammonium loading into $\mathrm{SH}$ and $\mathrm{BC}$ pools. Ammonium loading increased with increasing invertebrate biomass per volume $\left(F_{1,17}=5.70\right.$, $P=0.0289)$, which ranged from 0.8 to $28.1 \mathrm{~g} / \mathrm{L}$.

\section{Ammonium loading, herbivory, and macroalgal diversity}

Eleven macroalgal species were present in $\mathrm{SH}$ and BC pools: six Rhodophytes (Farlowia mollis, Mastocarpus papillatus, Mazzaella splendens, Odonthalia floccosa, Polysiphonia hendryi and Prionitis lanceolata); three Heterokontophytes (Fucus gardneri, Pelvetiopsis limitata, and Soranthera ulvoidea); and two Chlorophytes (Cladophora columbiana and Ulva californica) (see Scagel et al. 1993 for authorities). More species occurred in pools with higher rates of ammo-
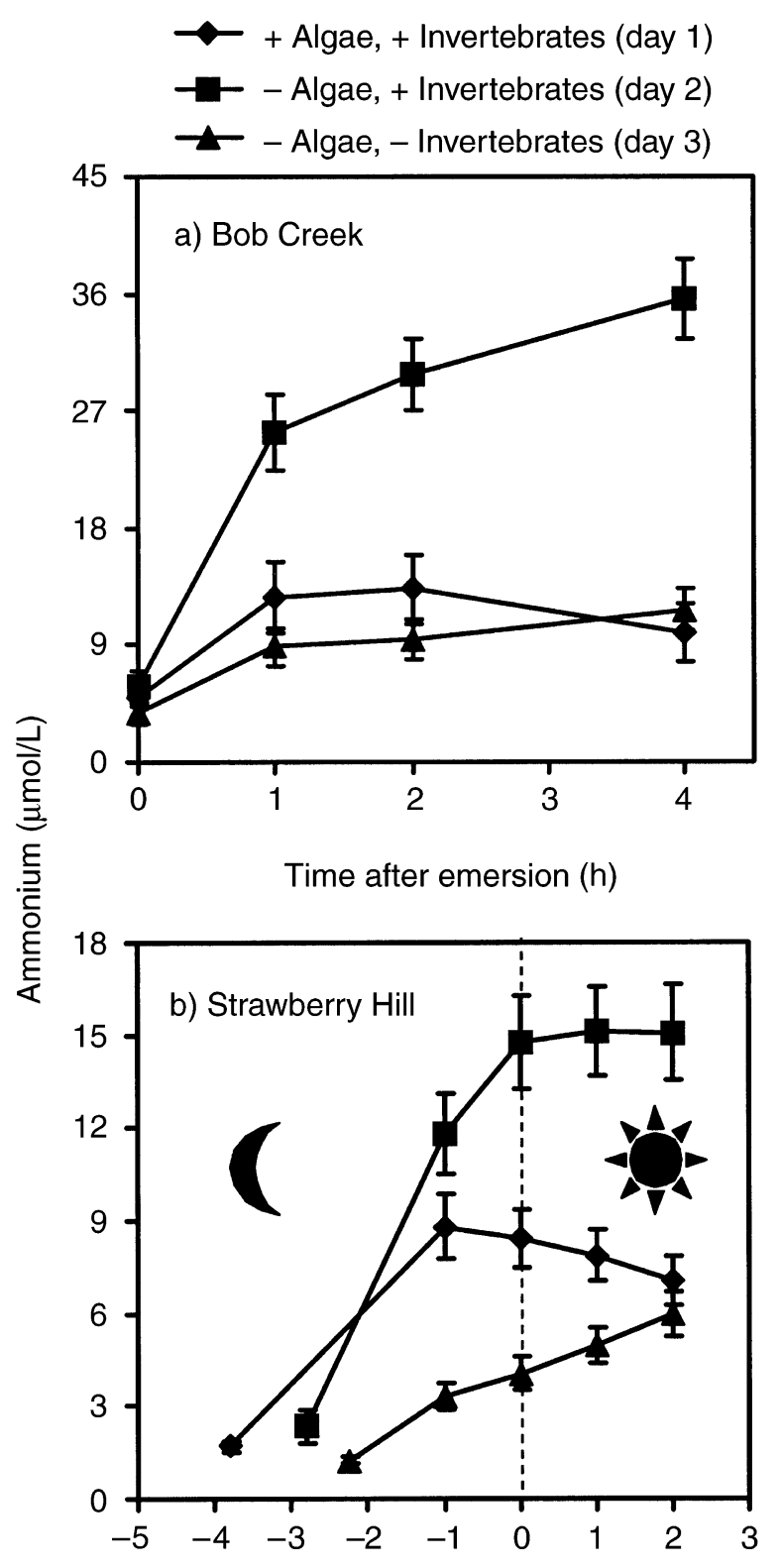

Time with respect to sunrise (h)

FIG. 1. Sequential removals of macroalgae and invertebrates influenced ammonium concentrations in tide pools. Values are means ( $\pm 1 \mathrm{SE}$ ). (a) Ammonium concentrations in Bob Creek pools $(n=10)$ were measured $0,1,2$, and $4 \mathrm{~h}$ after pool emersion. (b) Ammonium concentrations in Strawberry Hill pools $(n=10)$ were determined at $-1,0,1$, and $2 \mathrm{~h}$ before and after sunrise, and an initial sample was taken as the receding tide isolated each pool. Removals were conducted after each day's measurements and consisted of no removals on day 1 ; removal of algae on day 2; and removal of algae and invertebrates on day 3 .

nium loading (Fig. 2a). After accounting for site differences and the potential influence of pool surface area on species richness, a fourfold increase in the rate of ammonium loading was associated with a doubling in 


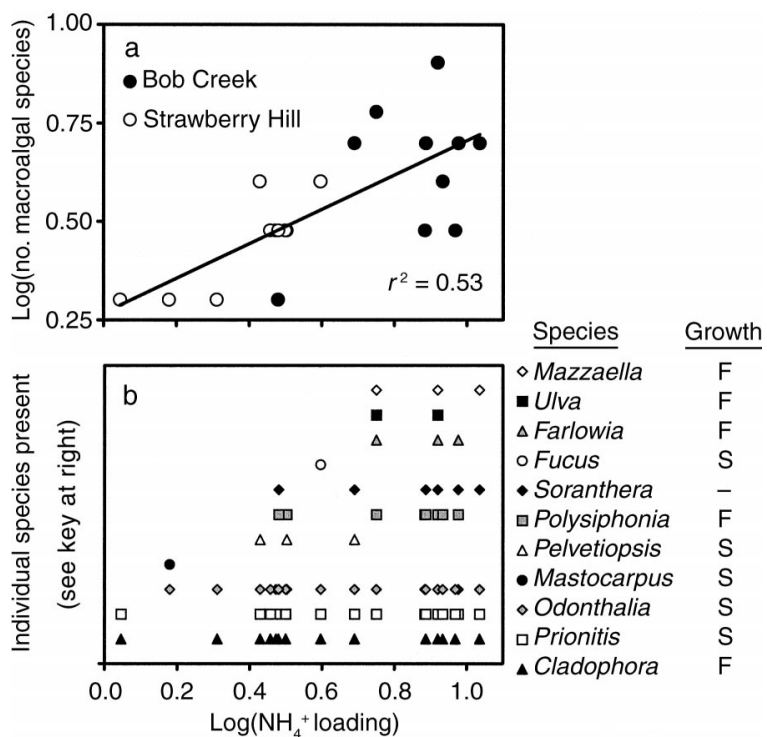

FIG. 2. Macroalgal diversity and growth, in relation to ammonium loading in tide pools. (a) Species richness increased with ammonium loading. (b) Macroalgal composition changed with ammonium loading, as slower growing species (S) with maximum growth rates $<0.05 \mathrm{~d}^{-1}$ were joined by faster growing species $(\mathrm{F})$ with growth rates $>0.05 \mathrm{~d}^{-1}$. Relative growth rates of macroalgal genera are based on Waaland (1977), Fujita et al. (1989), Phillips (1989), Nielsen and SandJensen (1990), and M. Bracken, unpublished data. $\mathrm{NH}_{4}{ }^{+}$loading was originally measured in units of $\mu \mathrm{mol} \cdot \mathrm{L}^{-1} \cdot \mathrm{h}^{-1}$.

the number of macroalgal species $(P=0.0135$; Table $1)$. Neither the site $(P=0.6453)$ nor the range of bottom surface areas at $\mathrm{SH}$ and $\mathrm{BC}\left(0.1\right.$ to $1.5 \mathrm{~m}^{2} ; P=$ 0.5490 ) influenced species richness (Table 1). Similarly, after accounting for site differences and ammonium loading rates, tide pool volume did not influence macroalgal richness $\left(F_{1,16}=1.33, P=0.2652\right)$. The increase in richness with ammonium loading was primarily additive: species present in pools with low ammonium loading rates were also present in pools with high loading rates, and new species occurred as loading rates increased (Fig. 2b). Many species that occurred in pools with low ammonium loading rates were slowgrowing perennials (e.g., Prionitis, Odonthalia, Mastocarpus, and Pelvetiopsis) (Waaland 1977, Fujita et al. 1989, Phillips 1989; M. Bracken, unpublished data). Most species "added" into pools at higher ammonium loading rates (e.g., Polysiphonia, Farlowia, Ulva, and Mazzaella) were characterized by higher growth rates (Waaland 1977, Nielsen and Sand-Jensen 1990). However, slow-growing species (growth rates $<0.05 \mathrm{~d}^{-1}$ ) dominated algal cover in all pools, regardless of ammonium loading ( $t=2.13$, $\mathrm{df}=19, P=0.0464)$.

Densities of turban snails (Tegula funebralis) in $\mathrm{SH}$ pools ranged from 0.0 to 33.8 individuals $/ \mathrm{m}^{2}$. Higher Tegula densities were associated with lower macroalgal abundance $(\mathrm{g} / \mathrm{L})\left(F_{1,7}=17.90, P=0.0039\right)$ in $\mathrm{SH}$ pools, but had no effect on richness $\left(F_{1,7}=0.01, P=\right.$
0.9081). Conversely, higher rates of ammonium loading were associated with increased macroalgal richness $\left(F_{1,7}=14.45, P=0.0067\right)$, but not algal abundance $\left(F_{1,7}=0.01, P=0.9240\right)$.

As the number of macroalgal species increased in tide pools, the biomass-specific ammonium uptake rate of the algal assemblage increased (Fig. 3). After accounting for differences between $\mathrm{SH}$ and $\mathrm{BC}$, a twofold increase in species richness was associated with a $50 \%$ increase in the biomass-specific uptake rate $\left(F_{1,17}=\right.$ $6.61, P=0.0199)$. This suggested that the additional species present at high nitrogen loading rates might have a greater capacity for uptake. We investigated this possibility by comparing the ammonium uptake rates of Ulva (a fast-growing species present only in pools characterized by high ammonium loading rates) and Prionitis (a slow-growing species present in virtually all SH and BC pools) (Fig. 4). Both species' biomassspecific uptake rates increased with increasing ammonium concentrations $\left(F_{1,25}=63.18, P<0.0001\right)$, but the uptake rate of Ulva increased more rapidly than that of Prionitis (ammonium $\times$ species interaction; $F_{1,25}$ $=20.39, P=0.0001$ ), indicating that Ulva was capable of higher uptake rates than Prionitis at higher ammonium concentrations.

\section{DISCUSSION}

\section{Nitrogen limitation in high-intertidal pools}

Nitrogen is the limiting nutrient in most marine ecosystems (Vitousek et al. 1997). The high productivity of Oregon coast nearshore ecosystems is associated with coastal upwelling, which transports nitrate-rich water to the surface (Bakun 1996); summer mean daily nitrate concentrations are $16.1 \pm 1.3 \mu \mathrm{mol} / \mathrm{L}$ (mean \pm $1 \mathrm{SE}$ ) in the nearshore ocean immediately adjacent to $\mathrm{SH}$ and $\mathrm{BC}$, and maximum concentrations exceed 30 $\mu \mathrm{mol} / \mathrm{L}$ (K. Nielsen and B. Menge, unpublished data). However, even in this highly productive ecosystem, nitrate can periodically become depleted for up to several days (Nielsen 2003), and nitrogen enrichment can increase phytoplankton biomass (Kudela and Dugdale 2000). Moreover, experimental additions of nutrients (nitrate, ammonium, and phosphate) to BB pools increased macroalgal diversity (functional group even-

TABLE 1. General linear model of the influence of ammonium loading, pool bottom surface area, and site on macroalgal species richness in tide pools.

\begin{tabular}{lrcccc}
\hline \hline \multicolumn{1}{c}{$\begin{array}{c}\text { Source of } \\
\text { variation }\end{array}$} & df & MS & $\begin{array}{c}\text { Parameter } \\
\text { estimates } \dagger\end{array}$ & $F$ & $P$ \\
\hline Site & 1 & 0.02 & -0.11 & 0.22 & 0.6453 \\
Surface area & 1 & 0.03 & 0.20 & 0.37 & 0.5490 \\
$\mathrm{NH}_{4}^{+}$loading & 1 & 0.64 & 0.49 & 7.70 & 0.0135 \\
Error & 16 & 0.08 & & & \\
\hline
\end{tabular}

$\dagger$ Due to $\log _{10}$ transformation of both response and explanatory variables, a fourfold increase in ammonium loading was associated with a doubling $\left(4^{0.49}\right.$-fold increase $)$ in species richness. 


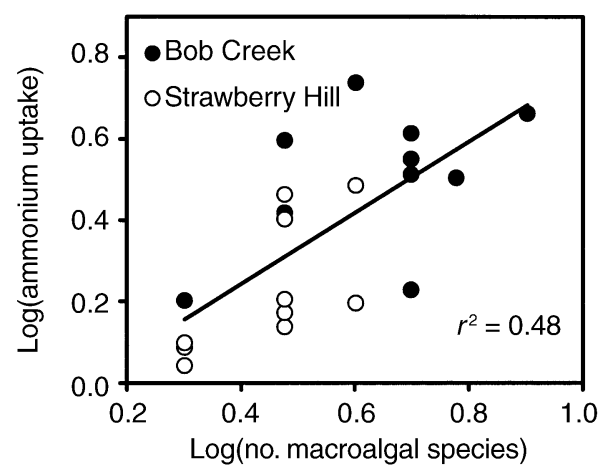

FIG. 3. Biomass-specific ammonium uptake rates as a function of species richness. Ammonium uptake was originally measured in units of $\mu \mathrm{mol} \cdot \mathrm{h}^{-1} \cdot \mathrm{g}^{-1}$.

ness) and biomass, suggesting that intertidal pools are nutrient-limited microhabitats within the nutrient-replete California Current ecosystem (Nielsen 2001, 2003).

Macroalgae rapidly deplete oceanic nitrate from pools during tidal emersion. We found that nitrate concentrations in BB pools declined linearly with time, becoming exhausted after about $7 \mathrm{~h}$ of isolation from the ocean. High-zone pools at $\mathrm{SH}$ and $\mathrm{BC}$ were typically isolated from the ocean for $12.8 \pm 0.2 \mathrm{~h}$ at a time, with emersion times ranging from 6.4 to $111.4 \mathrm{~h}$. Fewer than $5 \%$ of emersions occurred for less than the $7.2 \mathrm{~h}$ necessary for complete draw-down of all nitrate. Thus, macroalgae in high-intertidal pools experience extended periods without external nitrogen inputs. This contrasts sharply with the nitrogen environment experienced by the same species living lower on the shore, where algae are isolated from new nitrogen for only $1-4 \mathrm{~h} / \mathrm{d}$.

\section{Ammonium fluxes in tide pools}

Nutrient stress in high-zone pools can be ameliorated by a positive interaction: the excretion of ammonium by invertebrates and its utilization as a nitrogen source by macroalgae (Fig. 1). Positive interactions tend to occur when conditions are stressful: one species modifies the conditions responsible for the stress, allowing the other species to persist in an environment where it would not have thrived without its benefactor's intervention (Bertness and Callaway 1994). These interactions are particularly important in intertidal systems, where organisms experience stresses such as heat, desiccation, and nutrient limitation during tidal emersion (Thomas et al. 1987, Bertness and Leonard 1997). In high-zone pools, seawater retention eliminates desiccation stress, allowing low-zone macroalgae to exist higher on the shore. Salinity remained constant during tidal emersions of up to $6 \mathrm{~h}$ in the BB tide pools $(\mathrm{K}$. Nielsen, unpublished data), and thermal stress, if ecologically significant, should have resulted in a statistically significant effect of pool volume on diversity.
However, algae in high-intertidal pools are still susceptible to nutrient stress, which can be reduced by local-scale ammonium excretion. We quantified this positive influence of invertebrates on macroalgal diversity along a gradient in ammonium loading of 1.1$10.9 \mu \mathrm{mol} \cdot \mathrm{L}^{-1} \cdot \mathrm{h}^{-1}$.

\section{Ammonium loading, herbivory, and macroalgal diversity}

More macroalgal species occurred in pools with higher rates of ammonium loading (Fig. 2). This pattern contrasts with the results of local-scale studies of nutrient enrichment in terrestrial systems, where adding nutrients generally decreases the number of macrophyte species (Tilman 1987, Gough et al. 2000), but is consistent with results of nutrient additions in lownutrient marine systems (Worm et al. 2002). We suggest that this disparity reflects a unimodal relationship between diversity and productivity: increasing productivity is associated with increasing diversity to a point, after which diversity declines as productivity continues to increase (Tilman and Pacala 1993, Mittelbach et al. 2001, Chase and Leibold 2002). Especially in terrestrial systems, nutrient enrichments often begin at the peak of this unimodal relationship, because the species at a location have adapted to coexist at that location's level of productivity. Adding nutrients perturbs this coexistence, promoting the growth of aggressive competitors and leading to declines in diversity (Rosenzweig 1995).

High-intertidal pools are nitrate-depleted microhabitats within a nitrate-rich ecosystem. The species found in high-zone pools at $\mathrm{SH}$ and $\mathrm{BC}$ represented only a subset of the species found at lower tidal heights, where more frequent immersion is associated with increased nutrient availability. Surveys of low-intertidal macroalgae on emergent reefs at $\mathrm{SH}$ and $\mathrm{BC}$ suggest that up to 13 species can coexist in a $1-\mathrm{m}^{2}$ patch in the nutrientrich low-shore environment (G. Allison et al., unpublished data). Mid-zone pools at BB $\left(0.16 \mathrm{~m}^{2}\right)$ contained two to 17 species (Nielsen 1998). High-zone pools at $\mathrm{SH}$ and $\mathrm{BC}$ contained two to eight species, depending

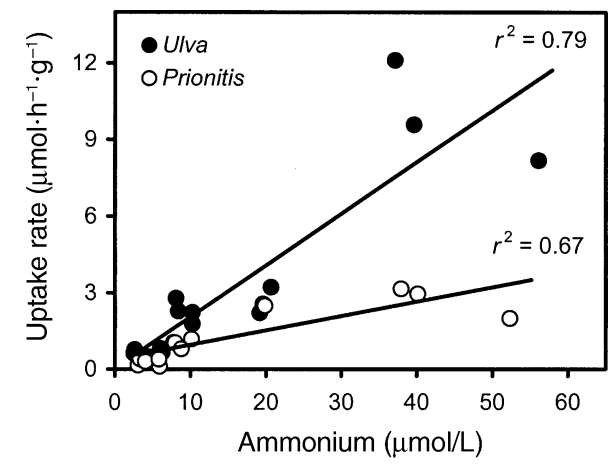

FIG. 4. Biomass-specific ammonium uptake rates of tide pool macroalgae: Ulva californica and Prionitis lanceolata. 
on ammonium loading rates. We hypothesize that as nutrient availability increases in high-intertidal pools, species richness has the potential to increase until it approximates the richness lower on the shore. Beyond a certain point, however, nutrients will exceed the maximum natural level of the system, nutrient additions will lead to domination by fast-growing ephemeral species, and richness will decline (Duarte 1995).

Herbivory also influences the diversity of tide pool macroalgae (Lubchenco 1978, Nielsen 2003), and the relationship between diversity and macrophyte productivity can be affected by consumer pressure (Huston 1994, Worm et al. 2002). While our results support a strong effect of herbivory on overall macroalgal abundances in tide pools, we found no evidence for an effect on diversity in these high-zone tide pools. Conversely, while macroalgal richness increased with ammonium loading, local-scale nutrient loading did not influence algal biomass. The densities of herbivores in SH highzone pools were relatively low $(19.3 \pm 3.3$ individuals/ $\mathrm{m}^{2}$ ), corresponding to densities in Nielsen's (2001, 2003) experimental herbivore reductions at BB, where nutrient loading strongly increased algal evenness. SH herbivore densities were sufficient to influence algal biomass, but not high enough to affect diversity. Topdown and bottom-up factors may affect different aspects of community structure in a context-dependent fashion: nutrients become increasingly important in the high intertidal zone (where nutrient limitation is most severe), while herbivores' effects on diversity are reduced (Menge and Olson 1990).

At higher ammonium loading rates, polysiphonous and foliose species (e.g., Polysiphonia, Farlowia, Ulva, and Mazzaella) occurred in the tide pools (Fig 2b). Slow-growing perennial species (e.g., Prionitis, Odonthalia, Pelvetiopsis, and Fucus), with high nitrogen storage capacities and low ammonium uptake capabilities (Fujita et al. 1989, Pedersen and Borum 1996, 1997), were more-or-less constant members of the tide pool communities we studied, while faster-growing ephemeral species occurred primarily during the summer (M. Bracken, personal observation). Thus, the observed relationship between invertebrate-mediated nutrient loading and diversity may be limited to the summer, when high irradiance levels and nutrient availability facilitate the growth of opportunistic ephemeral macroalgae.

The presence of polysiphonous and foliose species, which are characterized by high growth rates, surface area-to-volume ratios, and ammonium uptake rates (Waaland 1977, Nielsen and Sand-Jensen 1990, Pedersen and Borum 1997, Campbell 2001) and low nitrogen storage capacities (Pedersen and Borum 1996), was associated with increases in the macroalgal assemblages' rates of biomass-specific ammonium uptake (Fig. 3). Especially in pools characterized by high ammonium accumulation rates, where ammonium concentrations reached $\sim 25 \mu \mathrm{mol} / \mathrm{L}$, uptake rates of ephemeral, fast-growing species such as Ulva could be nearly three times higher than uptake rates of slowgrowing species such as Prionitis (Fig. 4). However, at ammonium concentrations $<14.6 \mu \mathrm{mol} / \mathrm{L}$, the biomass-specific uptake rates of Ulva and Prionitis were not different. While Prionitis occurred in pools spanning the observed range of ammonium loading rates and concentrations, Ulva only occurred where concentrations were $>15 \mu \mathrm{mol} / \mathrm{L}$. However, slow-growing species (especially Odonthalia and Prionitis) comprised the majority of macroalgal cover in all pools, regardless of ammonium loading rates, suggesting that even in pools with high loading rates, the nitrogen supply was not sufficient to allow domination of fast-growing species with higher nitrogen requirements (Pedersen and Borum 1996). An exception to this pattern was Cladophora, a fast-growing filamentous alga found in virtually all pools, regardless of ammonium loading rates (Fig. 2b). Observations and laboratory measurements of ammonium fluxes in Cladophora mats suggest that this alga harbors substantial biomasses of mesoand micro-heterotrophs within its filaments (M. Bracken, unpublished data). Micro-scale ammonium regeneration within Cladophora mats may meet its nutritional needs, allowing it to persist at lower levels of ammonium loading by tide pool macro-invertebrates.

The effects of local-scale nutrient additions on diversity appear to be context dependent. When nutrients are limiting, nutrient additions can increase diversity. However, adding nutrients to a nutrient-replete system promotes the growth of aggressive competitors, reducing diversity. Our results from this study and an earlier study (Nielsen 2003) are consistent with this model. High-zone pools are more limited by nutrients than mid-zone pools. Thus, a clear effect of nutrients on species richness was observed in the high zone (reported here), while nutrient additions in mid-zone pools, where species richness is already high, primarily influenced macroalgal evenness (Nielsen 2003). This pattern is analogous to the unimodal relationship between consumer abundance and diversity demonstrated by Lubchenco (1978), which resolved contradictions between experiments suggesting that removing consumers could increase (e.g., Worm et al. 2002, Nielsen 2003) or decrease (e.g., Paine 1966) resource-species diversity. In the case of consumer-mediated diversity patterns, the unimodal relationship requires selective consumption of the competitively dominant prey: resource-species diversity is highest at intermediate consumer densities because consumers are abundant enough to prevent overgrowth by competitive dominants, but not so abundant as to eliminate them. Similarly, the relationship between nutrient loading and macroalgal diversity relies on species' differences in growth and nutrient uptake (Huston 1994). Diversity peaks at intermediate nutrient availability because nutrient levels are sufficient to permit existence of fast- 
growing species with high nutrient requirements, but low enough to prohibit their domination.

\section{ACKNOWLEDGMENTS}

G. Boehlert, L. Weber, and P. Wheeler provided lab space and equipment at the Hatfield Marine Science Center. L. Petes and C. Sorte assisted with research. Comments from C. Harley, P. Jepson, J. Lubchenco, D. Lytle, P. McEvoy, B. Menge, R. Russell, V. Weis, S. Williams, and three anonymous reviewers greatly improved this manuscript. This research was conducted in partial fulfillment of the requirements for a $\mathrm{Ph}$.D. at Oregon State University (M. Bracken). Funding was provided by an NSF predoctoral fellowship (to M. Bracken), a Markham Research Award (to M. Bracken), an American Association of University Women Dissertation Fellowship (to K. J. Nielsen), Sigma-Xi Grants-in-Aid of Research (to K. J. Nielsen), a University Club Foundation Fellowship Award (to K. J. Nielsen), Oregon State University Zoology Research Funds (to K. J. Nielsen), an Andrew W. Mellon Foundation grant (to J. Lubchenco and B. Menge), and the Partnership for Interdisciplinary Studies of Coastal Oceans (PISCO). This is contribution number 151 from PISCO, a Long-Term Ecological Consortium supported by the David and Lucile Packard Foundation, and contribution number 2201 from Bodega Marine Laboratory, University of California-Davis.

\section{Literature Cited}

Bakun, A. 1996. Patterns in the ocean: ocean processes and marine population dynamics. California Sea Grant, La Jolla, California, USA.

Bertness, M. D., and R. Callaway. 1994. Positive interactions in communities. Trends in Ecology and Evolution 9:191193.

Bertness, M. D., and G. H. Leonard. 1997. The role of positive interactions in communities: lessons from intertidal habitats. Ecology 78:1976-1989.

Campbell, S. 2001. Ammonium requirements of fast-growing ephemeral macroalgae in a nutrient-enriched marine embayment (Port Phillip Bay, Australia). Marine Ecology Progress Series 209:99-107.

Chase, J. M., and M. A. Leibold. 2002. Spatial scale dictates the productivity-biodiversity relationship. Nature 416:427430.

Connell, J. H., and E. Orias. 1964. The ecological regulation of species diversity. American Naturalist 98:399-414.

Dethier, M. N. 1984. Disturbance and recovery in intertidal pools. Ecological Monographs 54:99-118.

Duarte, C. M. 1995. Submerged aquatic vegetation in relation to different nutrient regimes. Ophelia 41:87-112.

Dugdale, R. C., and J. J. Goering. 1967. Uptake of new and regenerated forms of nitrogen in primary productivity. Limnology and Oceanography 12:196-206.

Fujita, R. M., P. A. Wheeler, and R. L. Edwards. 1989. Assessment of macroalgal nitrogen limitation in a seasonal upwelling region. Marine Ecology Progress Series 53:293303.

Gough, L., C. W. Osenberg, K. L. Gross, and S. L. Collins. 2000. Fertilization effects on species density and primary productivity in herbaceous plant communities. Oikos 89: 428-439.

Hall, S. J., S. A. Gray, and Z. L. Hammett. 2000. Biodiversity-productivity relations: an experimental evaluation of mechanisms. Oecologia 122:545-555.

Harlin, M. M., and P. A. Wheeler. 1985. Nutrient uptake. Pages 493-508 in M. M. Littler and D. Littler, editors. Ecological field methods: macroalgae. Handbook of phycological methods. Cambridge University Press, Cambridge, UK.

Harrison, P. J., and L. D. Druehl. 1982. Nutrient uptake and growth in the Laminariales and other macrophytes: a con- sideration of methods. Pages $99-120$ in L. M. Srivastava, editor. Synthetic and degradative processes in marine macrophytes. Walter de Gruyter, Berlin, Germany.

Hurd, C. L. 2000. Water motion, marine macroalgal physiology, and production. Journal of Phycology 36:453-472.

Huston, M. A. 1994. Biological diversity: the coexistence of species on changing landscapes. Cambridge University Press, Cambridge, UK.

Jensen, S. L., and G. Muller-Parker. 1994. Inorganic nutrient fluxes in anemone-dominated tide pools. Pacific Science 48:32-43.

Johnson, D. S., and A. F. Skutch. 1928. Littoral vegetation on a headland of Mt. Desert Island, Maine. II. Tide pools and the environment and classification of submersible plant communities. Ecology 9:307-338.

Kassen, R., A. Buckling, G. Bell, and P. B. Rainey. 2000. Diversity peaks at intermediate productivity in a laboratory microcosm. Nature 406:508-512.

Kudela, R. M., and R. C. Dugdale. 2000. Nutrient regulation of phytoplankton productivity in Monterey Bay, California. Deep-Sea Research II 47:1023-1053.

Leibold, M. A. 1999. Biodiversity and nutrient enrichment in pond plankton communities. Evolutionary Ecology Research 1:73-95.

Lubchenco, J. 1978. Plant species diversity in a marine intertidal community: importance of herbivore food preference and algal competitive abilities. American Naturalist 112:23-39.

Menge, B. A., B. A. Daley, P. A. Wheeler, E. Dahlhoff, E. Sanford, and P. T. Strub. 1997a. Benthic-pelagic links and rocky intertidal communities: bottom-up effects on topdown control? Proceedings of the National Academy of Sciences (USA) 94:14530-14535.

Menge, B. A., B. A. Daley, P. A. Wheeler, and P. T. Strub. 1997b. Rocky intertidal oceanography: an association between community structure and nearshore phytoplankton concentration. Limnology and Oceanography 42:57-66.

Menge, B. A., and A. M. Olson. 1990. Role of scale and environmental factors in regulation of community structure. Trends in Ecology and Evolution 5:52-57.

Mittelbach, G. G., C. F. Steiner, S. M. Scheiner, K. L. Gross, H. L. Reynolds, R. B. Waide, M. R. Willig, S. I. Dodson, and L. Gough. 2001. What is the observed relationship between species richness and productivity? Ecology 82: 2381-2396.

Naeem, S. 2002. Ecosystem consequences of biodiversity loss: the evolution of a paradigm. Ecology 83:1537-1552.

Nielsen, K. J. 1998. Bottom-up and top-down forces in tidepools: the influence of nutrients, herbivores, and wave exposure on community structure. Dissertation. Oregon State University, Corvallis, Oregon, USA.

Nielsen, K. J. 2001. Bottom-up and top-down forces in tide pools: test of a food chain model in an intertidal community. Ecological Monographs 71:187-217.

Nielsen, K. J. 2003. Nutrient loading and consumers: agents of change in open-coast macrophyte assemblages. Proceedings of the National Academy of Sciences (USA) 100: 7660-7665.

Nielsen, S. L., and K. Sand-Jensen. 1990. Allometric scaling of maximal photosynthetic growth rate to surface/volume ratio. Limnology and Oceanography 35:177-181.

Paine, R. T. 1966. Food web complexity and species diversity. American Naturalist 100:65-75.

Parsons, T. R., Y. Maita, and C. M. Lalli. 1984. A manual of chemical and biological methods for seawater analysis. Pergamon, New York, New York, USA.

Pedersen, M. F., and J. Borum. 1996. Nutrient control of algal growth in estuarine waters: nutrient limitation and the importance of nitrogen requirements and nitrogen storage 
among phytoplankton and species of macroalgae. Marine Ecology Progress Series 142:261-272.

Pedersen, M. F., and J. Borum. 1997. Nutrient control of estuarine macroalgae: growth strategy and the balance between nitrogen requirements and uptake. Marine Ecology Progress Series 161:155-163.

Phillips, N. 1989. The function of salinity and temperature in the distribution of Mastocarpus papillatus (C. Ag.) Kutzing in the San Francisco Bay. Thesis. Sonoma State University, Rohnert Park, California, USA.

Pimm, S. L., G. J. Russell, J. L. Gittelman, and T. M. Brooks. 1995. The future of biodiversity. Science 269:347-350.

Ramsey, F. L., and D. W. Schafer. 1997. The statistical sleuth: a course in methods of data analysis. Duxbury Press, Belmont, California, USA.

Riebesell, J. F. 1974. Paradox of enrichment in competitive systems. Ecology 55:183-187.

Rosenzweig, M. L. 1995. Species diversity in space and time. Cambridge University Press, Cambridge, UK.

Scagel, R. F., P. W. Gabrielson, D. J. Garbary, L. Golden, M. W. Hawkes, S. C. Lindstrom, J. C. Oliveira, and T. B. Widdowson. 1993. A synopsis of the benthic marine algae of British Columbia, Southeast Alaska, Washington, and Oregon. University of British Columbia, Vancouver, Canada.

Solórzano, L. 1969. Determination of ammonia in natural waters by the phenolhypochlorite method. Limnology and Oceanography 14:799-801.

Taylor, R. B., J. T. A. Peek, and T. A. V. Rees. 1998. Scaling of ammonium uptake by seaweeds to surface area:volume ratio: geographical variation and the role of uptake by passive diffusion. Marine Ecology Progress Series 169:143148.

Taylor, R. B., and T. A. V. Rees. 1998. Excretory products of mobile epifauna as a nitrogen source for seaweeds. Limnology and Oceanography 43:600-606.
Thomas, T. E., P. J. Harrison, and D. H. Turpin. 1987. Adaptations of Gracilaria pacifica (Rhodophyta) to nitrogen procurement at different intertidal locations. Marine Biology 93:569-580.

Tilman, D. 1987. Secondary succession and the pattern of plant dominance along experimental nitrogen gradients. Ecological Monographs 57:189-214.

Tilman, D., and S. Pacala. 1993. The maintenance of species richness in plant communities. Pages 13-25 in R. E. Ricklefs and D. Schluter, editors. Species diversity in ecological communities. University of Chicago Press, Chicago, Illinois, USA.

Vitousek, P. M. 1994. Beyond global warming: ecology and global change. Ecology 75:1861-1876.

Vitousek, P. M., J. D. Aber, R. W. Howarth, G. E. Likens, P. A. Matson, D. W. Schindler, W. H. Schlesinger, and D. G. Tilman. 1997. Human alteration of the global nitrogen cycle: sources and consequences. Ecological Applications 7: 737-750.

Waaland, J. R. 1977. Growth of Pacific Northwest marine algae in semi-closed culture. Pages 117-137 in R. W. Krauss, editor. The marine plant biomass of the Pacific Northwest coast. Oregon State University Press, Corvallis, Oregon, USA.

Wheeler, W. N. 1982. Nitrogen nutrition of Macrocystis. Pages 121-137 in L. M. Srivastava, editor. Synthetic and degradative processes in marine macrophytes. Walter de Gruyter, Berlin, Germany.

Williams, S. L., and R. C. Carpenter. 1988. Nitrogen-limited primary productivity of coral reef algal turfs: potential contribution of ammonium excreted by Diadema antillarum. Marine Ecology Progress Series 47:145-152.

Worm, B., H. K. Lotze, H. Hillebrand, and U. Sommer. 2002. Consumer versus resource control of species diversity and ecosystem functioning. Nature 417:848-851. 